\title{
Intercomparison of Solid Precipitation Derived from the Weighting Rain Gauge and Optical Instruments in the Interior Qinghai-Tibetan Plateau
}

\author{
Lele Zhang, ${ }^{1,2}$ Lin Zhao, ${ }^{1}$ Changwei Xie,, Guangyue Liu, ${ }^{1}$ Liming Gao, ${ }^{2,3}$ Yao Xiao, ${ }^{1}$ \\ Jianzong Shi, ${ }^{1}$ and Yongping Qiao ${ }^{1}$ \\ ${ }^{1}$ Cryosphere Research Station on the Qinghai-Tibet Plateau, State Key Laboratory of Cryospheric Sciences, \\ Cold and Arid Regions Environmental and Engineer Research Institute, Chinese Academy of Sciences, Lanzhou 730000, China \\ ${ }^{2}$ University of Chinese Academy of Science, Beijing 10049, China \\ ${ }^{3}$ Gansu Data Engineering and Technology Research Center for Resources and Environment, Lanzhou 73000, China
}

Correspondence should be addressed to Lin Zhao; linzhao@lzb.ac.cn

Received 19 May 2015; Revised 5 July 2015; Accepted 6 July 2015

Academic Editor: Gabriele Curci

Copyright (C) 2015 Lele Zhang et al. This is an open access article distributed under the Creative Commons Attribution License, which permits unrestricted use, distribution, and reproduction in any medium, provided the original work is properly cited.

\begin{abstract}
Due to the light precipitation and strong wind in the cold season, it is hard to get credible solid precipitation on the QinghaiTibetan plateau (QTP). To address this issue, two kinds of optical instruments, the Thies Laser Precipitation Monitor (LPM) and OTT laser-optical Particle Size Velocity (Parsivel), were used on QTP. The measured precipitation was compared with the precipitation derived from Geonor T-200B precipitation gauge (Geonor). The results showed that Geonor was hard to catch light precipitation (precipitation amount was less than $1 \mathrm{~mm}$ during a single event) when the wind speeds were higher than $3.5 \mathrm{~m} / \mathrm{s}$. Even when the wind speeds were smaller than $3.5 \mathrm{~m} / \mathrm{s}$, about $44 \%$ of such light precipitation events were not recorded by Geonor. The optical instruments had much better performance in recording light precipitation. Three methods were used to correct Geonor measurements of daily solid precipitation and the corrected values were set as reference for assessing the performance of LPM and Parsivel; the results showed that LPM had good performance in measuring the solid precipitation but Parsivel overestimated the precipitation amount. Methods for correcting Geonor's hourly solid precipitation and recalculating Parsivel's solid precipitation amount were also proposed in this paper.
\end{abstract}

\section{Introduction}

Accurate precipitation is important for better understanding the climate change and water cycle [1-4], and it is also a crucial component of hydrologic and climatologic models [46]. Currently, the precipitation is mainly measured by different kinds of rain gauges; however, it is generally recognized that the gauge-measured precipitation has systematic errors including wetting, evaporation losses, and wind-induced undercatch [7-9]. Especially the solid precipitation, the measurement errors frequently range from $20 \%$ to $50 \%$ due to undercatch in windy conditions [10]. In order to get the true solid precipitation, the World Meteorological Organization (WMO) carried out a series of programs. In the third WMO precipitation measurement intercomparison (1986-1993), the Double Fence International Reference (DFIR) with a shielded Tretyakov gauge was designated as the reference standard snow gauges [11]. Since 2012, the WMO Commission for Instruments and Methods of Observation organized the Solid Precipitation Intercomparison Experiment (SPICE); the main objectives of the project are to define and validate the field references for gauge intercomparison and to assess the automatic systems used in the operational networks for solid precipitation observations [12]. Under these projects, the gauge undercatch of solid precipitation had greatly improved in most areas of the global. In China, Ye et al. [13] corrected the precipitation data over China and reported an approximately $16 \%$ increase in mean yearly precipitation 
during 1951-2004. Ding et al. [14] compared the measured and corrected precipitation data over China during 1951-1998 and found that bias corrections of precipitation lead to an $8 \%$ overall enhancement of yearly precipitation trends over China. Ma et al. [15] corrected the precipitation data by using different kinds of error correction procedures in the Third Pole Environment (TPE) region and found that the average annual precipitation has increased from a minimum of $4 \mathrm{~mm}$ to a maximum of $409 \mathrm{~mm}$ in this region. However, no special attention had been paid on the solid precipitation correction in the interior QTP until now [16].

QTP is known for its large sensible and latent heating effects on the troposphere over Asia. Quantitative evaluation of area precipitation is one of the important aspects for estimating latent heating and understanding the water cycle processes over this unique highland [17]. Compared with the other regions, the climate in the interior of QTP is special; the wind is strong and the light precipitation is dominant in winter, and the manual observation is unrealistic during this period due to the severe weather conditions, so it is nearly impossible to obtain the light solid precipitation from the traditional rain gauges.

Sugiura et al. [8] first introduced a snow particle counter (SPC) to solid precipitation measurement and proposed that the optical instruments like SPC should be used in solid precipitation measurements in the Arctic. Compared with SPC, LPM and Parsivel are kinds of more mature optical products and were well tested in liquid precipitation measurements before [18-21]. Furthermore, both of LPM and Parsivel had been used by the WMO for solid precipitation measurement in the SPICE project. Because LPM and Parsivel use the light beam for precipitation monitoring, the windinduced precipitation will be much smaller. Furthermore, the minimum precipitation intensity derived from the LPM and Parsivel is $0.005 \mathrm{~mm} / \mathrm{h}$ and $0.001 \mathrm{~mm} / \mathrm{h}$, respectively; it seems that the optical instruments will be most suitable for solid precipitation measurement in the interior QTB. However, no attention had been paid to whether they can be used for the solid precipitation observation in these regions until now.

In this study, we analyzed solid precipitation derived from Geonor and two kinds of optical instruments (Parsivel and LPM) at three meteorological stations in the Beiluhe (BLH), Tanggula (TGL), and Wudaoliang (WDL) lie in the interior QTP. Considering the old version of Parsivel has large error when measuring snow [22], the two Parsivel instruments used in this study are the latest version $\left(\right.$ Parsivel $\left.^{2}\right)$. Our goals are (1) investigating Geonor's deficiency in recording the light solid precipitation and (2) assessing the performance of optical instruments in measuring the solid precipitation in the interior QTP. Finally, we hope to get the more reliable solid precipitation data in these regions.

The paper is organized as follows. Section 2 introduces the basic conditions and the instruments in the study sites; the correcting methods for Geonor's daily solid precipitation are also introduced in this section. Section 3 compares the solid precipitation derived from the different instruments and the performance of Geonor in recording light precipitation is also discussed in this section. In Section 4, a statistic method for determining Parsivel's snow particles diameter correction factor $(\alpha)$ is proposed and the Parsivel solid precipitation amounts are recalculated. The discussions and conclusions are in Section 5.

\section{Methodology}

2.1. Study Sites. The observation stations chosen in this study are Beiluhe (BLH; $92.9^{\circ} \mathrm{E}, 34.8^{\circ} \mathrm{N}, 4600 \mathrm{~m}$ above sea level), Tanggula (TGL; $91.9^{\circ} \mathrm{E}, 33.1^{\circ} \mathrm{N}, 5100 \mathrm{~m}$ above sea level), and Wudaoliang (WDL; $93.1^{\circ} \mathrm{E}, 35.2^{\circ} \mathrm{N}, 4783 \mathrm{~m}$ above sea level). All of the three stations are located in the interior QTP (Figure 1). Based on previous observations, the mean annual air temperature (MAAT) in $\mathrm{BLH}$ is $-3.8^{\circ} \mathrm{C}$, with the highest value of $21.3^{\circ} \mathrm{C}$ in mid-July and lowest value of $-21.4^{\circ} \mathrm{C}$ in later January $[23,24]$. In TGL station, the MAAT is about $-4.1^{\circ} \mathrm{C}$ and its highest and lowest values are $16.2^{\circ} \mathrm{C}$ and $-30.5^{\circ} \mathrm{C}$ [25]. The MAAT in WDL is about $-5.1^{\circ} \mathrm{C}$ and maximum and minimum air temperature are $20.1^{\circ} \mathrm{C}$ and $-26.5^{\circ} \mathrm{C}$ [26]. The mean annual precipitation in the three stations are $368 \mathrm{~mm}$, $436.7 \mathrm{~mm}$, and $294.8 \mathrm{~mm}$, respectively [26, 27]. Due to the summer monsoon generally occurring from May to October, the precipitation events on the QTP mainly occur during the period from June to September. Like most areas on the QTP, the cold season of the three stations is long and the wind speeds during this periods are large, the instantaneous wind speed can reach to larger than $15 \mathrm{~m} / \mathrm{s}$.

In the three stations, the routine meteorological parameters like wind $(2 \mathrm{~m}, 5 \mathrm{~m}$, and $10 \mathrm{~m})$, air temperature $(2 \mathrm{~m}$, $5 \mathrm{~m}$, and $10 \mathrm{~m})$, humidity $(2 \mathrm{~m}, 5 \mathrm{~m}$, and $10 \mathrm{~m})$, precipitation, and solar radiation had been monitored since the early 21 st century. The rain gauge used in the TGL and WDL stations is Geonor, but in the BLH station is TE525 tipping-bucket rain gauge. In order to get the more detailed and accurate precipitation information, a LPM and a Geonor precipitation gauge were set in the BLH station in 2011 and 2012 separately. In the end of 2014, two Parsivel instruments had been installed in the TGL and WDL stations. In this study, the Geonor precipitation data were recorded every one hour in BLH station and every 30 minutes in TGL and WDL stations. In order to understand the microscopic information of the precipitation, the LPM and Parsivel data were recorded every minute. All of the data were logged by the CR23X or CR3000 data logger (Campbell Scientific Inc.).

2.2. Introduction of Instruments. The LPM uses the light beam for precipitation monitoring. Every time when precipitation particles pass through the sensing volume, it is capable of measuring their diameter and falling velocity [20]. From these measurements, it identifies the type of precipitation and calculates precipitation rate, drop-size distribution, and some other parameters. Bloemink and Lanzinger [18] compared the precipitation type derived from LPM with the Vaisala FD12P Present Weather Sensor and proposed the LPM can identify the precipitation accurately.

OTT Parsivel is also a laser-based optical disdrometer for simultaneously measuring the size and velocity of all types of hydrometeors during precipitation [21]. Its operating 


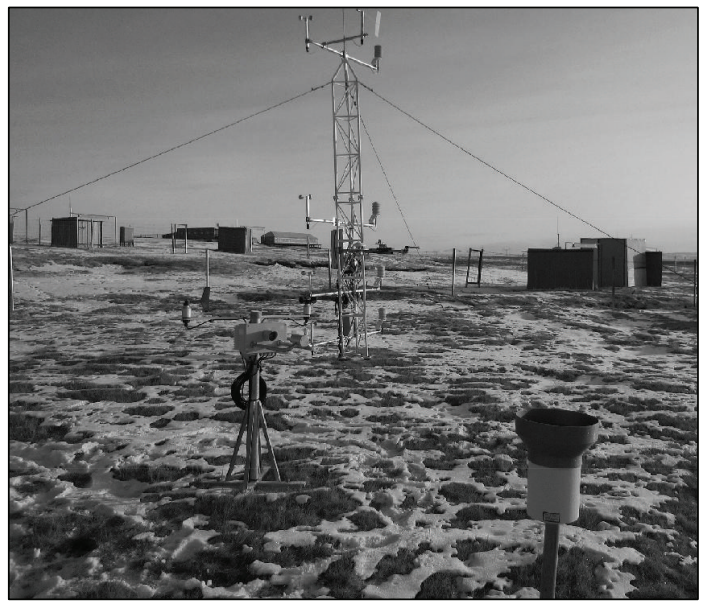

(a)

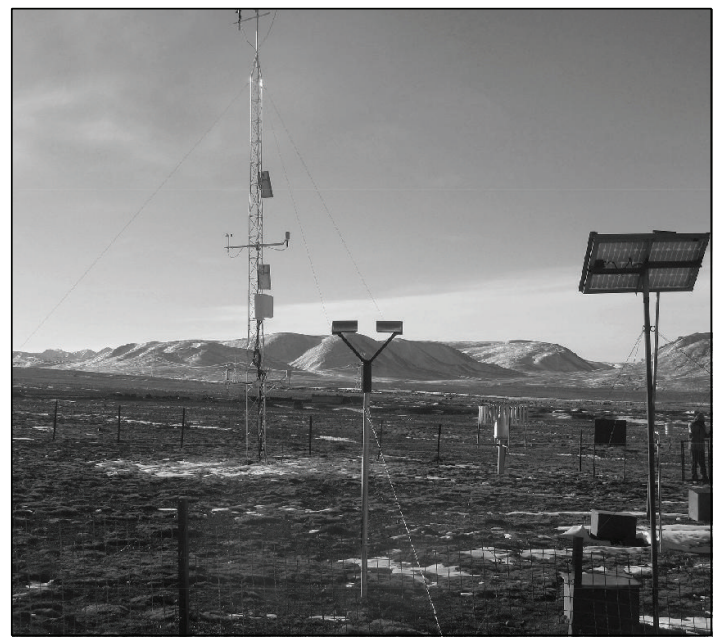

(b)
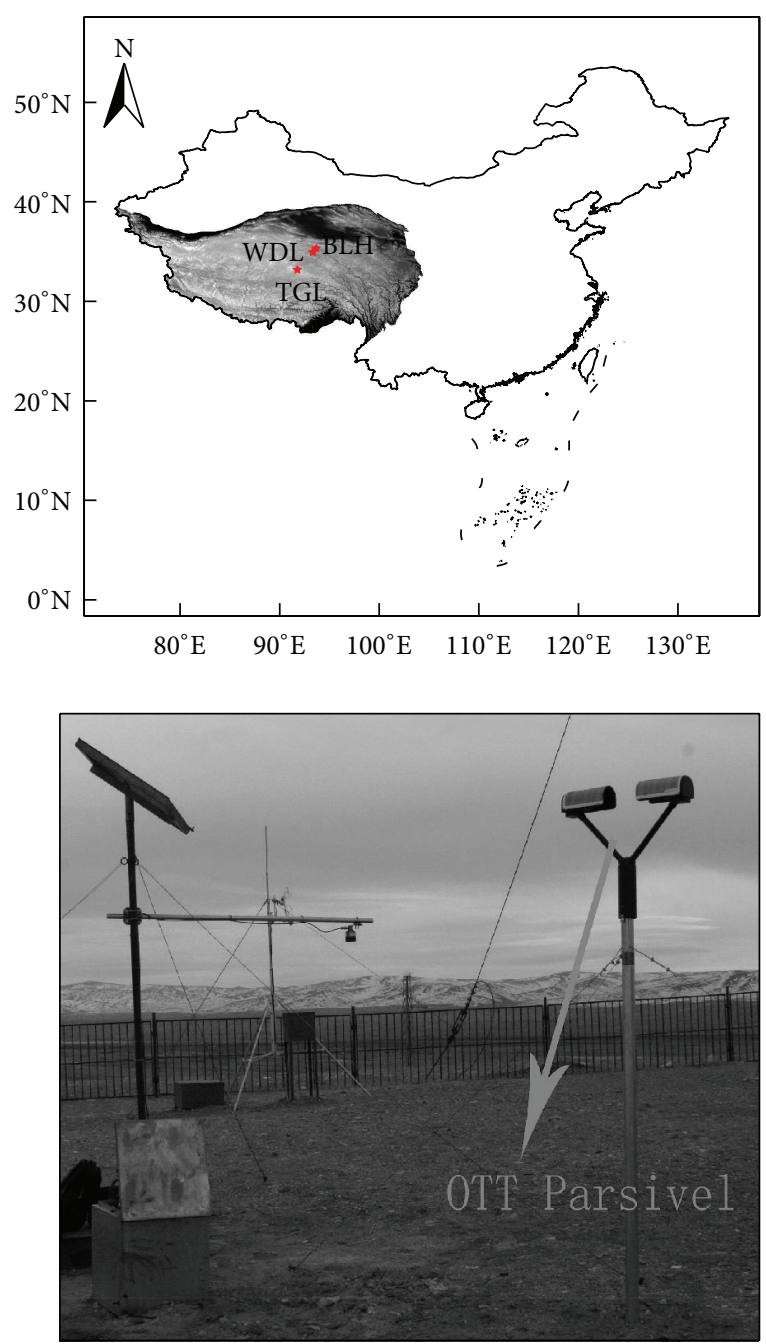

(c)

FIgURE 1: Location of the observation site and precipitation observation devices. (a) BLH, (b) TGL, and (c) WDL.

principle is similar to LPM, and the measurement area is $54 \mathrm{~cm}^{2}$, a little larger than LPM. The sensor determines the size and velocity of a hydrometeor by measuring the light extinction caused by the hydrometeor falling through the light sheet. The hydrometeor is then classified into 32 classes of sizes and velocity. From the size and velocity distribution information over the measurement period, the precipitation type, rate, and amount are determined.

Geonor is an automated weighing storage gauge which is widely used in the interior QTP. It continuously measures the weight of accumulated snowfall in a reservoir containing antifreeze solution and oil which melt the snow and reduce evaporation. The reservoir is suspended on a wire strain gauge which vibrates at a frequency proportional to the applied strain. The reservoir and strain gauge are in a protective housing which is surrounded by the Alter-shield. The Geonor has a resolution of $0.1 \mathrm{~mm}$ SWE and an accuracy of $0.1 \%$ [28].
2.3. Methods for Correcting Geonor Solid Precipitation. Geonor is widely used in the Arctic and QTP regions. Like the other precipitation gauges, Geonor's catch efficiency (CE) is also highly affected by the wind. Many scholars had proposed the correction methods for Geonor; the widely used correction methods were proposed by Smith [29] and MacDonald and Pomeroy [30]:

$$
\begin{aligned}
& \mathrm{CE}_{\text {Geonor }}=\frac{P_{\text {Geonor }}}{P_{\text {DFIR }}}=\exp (-0.2 \mathrm{WS}), \\
& \mathrm{CE}_{\text {Geonor }}=\frac{P_{\text {Geonor }}}{P_{c \text {-Nipher }}}=1.01 \exp (-0.09 \mathrm{WS}) .
\end{aligned}
$$

Equation (1) was proposed by Smith and (2) was by MacDonald and Pomeroy. Both of the two methods had been widely used and proven effective in improving the hydrological simulation [31-36]. 


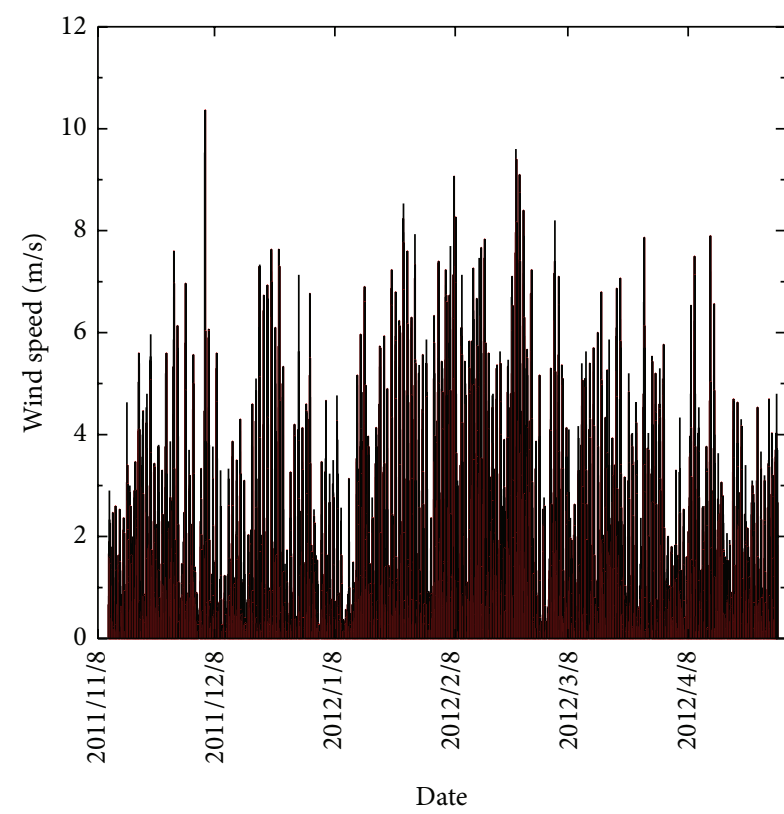

(a)

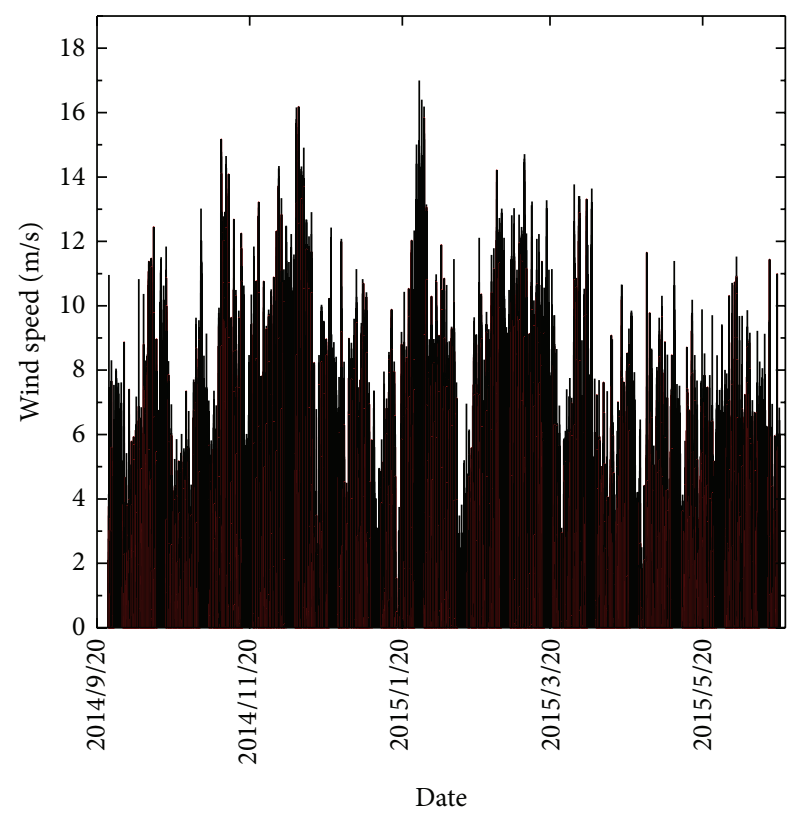

(b)

Figure 2: Wind speed during the study periods in (a) BLH and (b) TGL stations.

In the interior QTP, Zhao et al. [37] had also proposed the correction formula:

$$
\mathrm{CE}_{\mathrm{Geonor}}=\frac{P_{\mathrm{Geonor}}}{P_{c \text {-CSPG }}}=\exp (-0.135 \mathrm{WS}) .
$$

In the equations above, $\mathrm{CE}_{\mathrm{Geonor}}$ is solid precipitation catch efficiency of Geonor, $P_{\text {Geonor }}$ is the daily precipitation recorded by Geonor, $P_{\mathrm{DFIR}}$ is precipitation recorded by the double fence intercomparison reference (DFIR), and $P_{c \text {-Nipher }}$ and $P_{c-\text { CSPG }}$ are precipitation from corrected Nipher and Chinese standard precipitation gauge (CSPG), respectively. Adjustment procedures for Nipher and CSPG rain gauge had been developed by the WMO $[38,39]$. WS is the wind speed at gauge height measured in $\mathrm{m} / \mathrm{s}$. In BLH, there is a wind speed sensor at the gauge height. In the TGL and WDL, the wind speeds at the gauge height are calculated by using data at $2 \mathrm{~m}$ height based on the method proposed by Zhao et al. [37]:

$$
\mathrm{WS}=\left[\frac{\lg \left(h / z_{0}\right)}{\lg \left(H / z_{0}\right)}\right] \mathrm{WS}_{2 \mathrm{~m}}
$$

where WS is the wind speed at the gauge height, $h$ is the gauge height $(\mathrm{m}), z_{0}$ is surface roughness $(\mathrm{m}), \mathrm{He}$ et al. [28] and Zhao et al. [37] set $z_{0}$ as $0.01 \mathrm{~m}$ in cold season in the interior QTP, $H$ is the wind sensor installed height (2 $\mathrm{m}$ in this study), and $\mathrm{WS}_{2 \mathrm{~m}}$ is the wind speed at $2 \mathrm{~m}$ height.

The formulas (1)-(3) assume the DFIR as the "true" precipitation substantially. Yang [12] compared the precipitation derived from DFIR and the Bush Gauge and found that the Bush Gauge measures $20-50 \%$ more snow than the DFIR for wind speeds of $6-7 \mathrm{~m} / \mathrm{s}$. He also proposed the correction methods for DFIR. For dry snow, the formula is as follows:

$$
\frac{P_{\text {Bush }}}{P_{\text {DFIR }}}=100+0.171 \mathrm{WS}^{2}+0.2 \mathrm{WS}
$$

\section{Results}

3.1. Overview of Data. In the BLH station, observations were carried out from 2011/11/11 to 2012/4/30 and from 2012/11/1 to 2013/5/16. During the first period, the Geonor precipitation gauge was not installed in the BLH site; Geonor precipitation data were obtained from a meteorological station nearby (set by the State Key Laboratory of Frozen Soil Engineering, Cold and Arid Regions Environmental and Engineering Research Institute, Chinese Academy of Sciences, less than $1 \mathrm{~km}$ far from our site). During the second period, 33 days were not observed for the power supply reason. In TGL and WDL stations, the Parsivel instruments worked very well after installation and the data were collected every two months; the data of the two stations used in this study were from 2014/10/1 to $2015 / 4 / 30$ and from $2014 / 10 / 1$ to $2015 / 2 / 3$, respectively. During the study periods, the winds were strong and the instantaneous wind speed can reach to larger than $10 \mathrm{~m} / \mathrm{s}$ in BLH and $16 \mathrm{~m} / \mathrm{s}$ in TGL (Figure 2). Due to the high frequency light precipitation and the strong wind, processing solid precipitation data from Geonor precipitation gauge was also hard work. In this study, we processed the data carefully and used the optical instruments data as the standard for the judgment of precipitation events.

During the study periods, the precipitation days recorded by Geonor and the optical instruments were different (Figure 3). In the BLH station, LPM recorded 79 and 47 


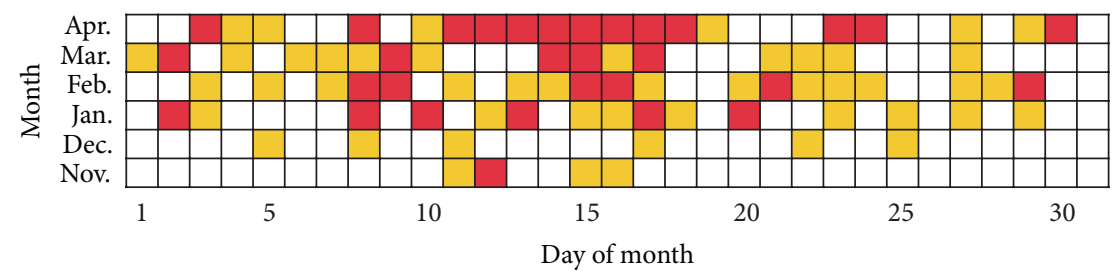

$\square$ No precipitation or no record

$\square$ Only LPM or Parsivel records precipitation

$\square$ Both of Geonor and optical instruments record precipitation

(a)

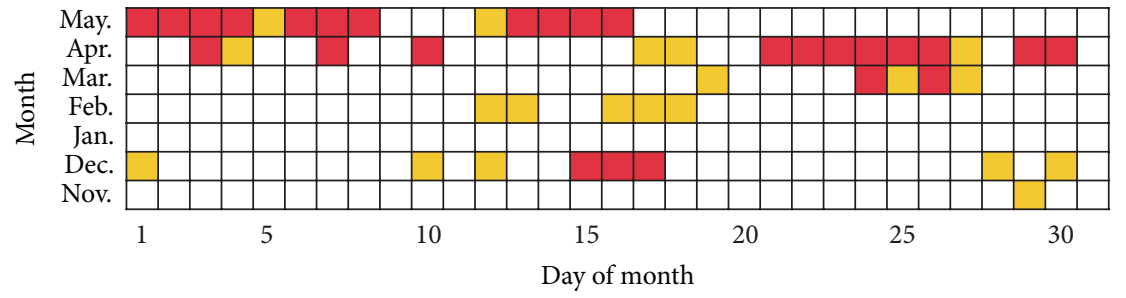

$\square$ No precipitation or no record

$\square$ Only LPM or Parsivel records precipitation

$\square$ Both of Geonor and optical instruments record precipitation

(b)

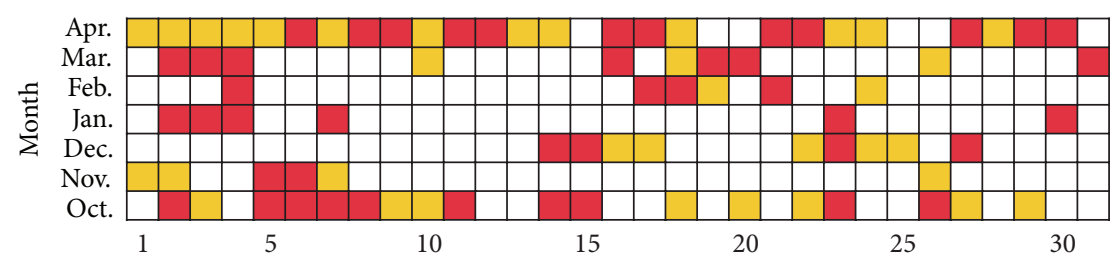

Day of month

$\square$ No precipitation or no record

$\square$ Only LPM or Parsivel records precipitation

Both of Geonor and optical instruments record precipitation

(c)

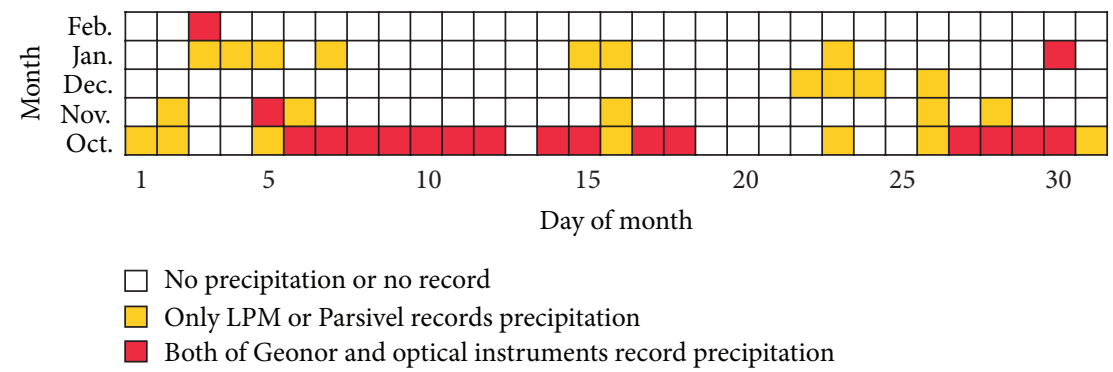

(d)

FIGURE 3: Precipitation days recorded by different instruments (a) from 2011/11/11 to 2012/4/30 and (b) from 2012/11/1 to 2013/5/16 in BLH, (c) from 2014/10/1 to 2015/4/30 in TGL, and (d) from 2014/10/1 to 2015/4/3 in WDL.

precipitation days during the two periods, but Geonor only recorded 31 and 27 precipitation days. In the TGL station, the precipitation days were 45 and 80 recorded by Geonor and Parsivel, respectively. In the WDL station, Parsivel recorded 41 while Geonor only recorded 18 precipitation days. In order to find which instrument was more credible, we chose a precipitation event during 2014/11/2 in TGL station (Figure 4); the Parsivel recorded $4.44 \mathrm{~mm}$ precipitation while the Geonor recorded no precipitation. By comparing the radiation and albedo with the before and the proceeding day, we found that both the global and net radiation decreased on November 2, and the albedo increased in the afternoon. 


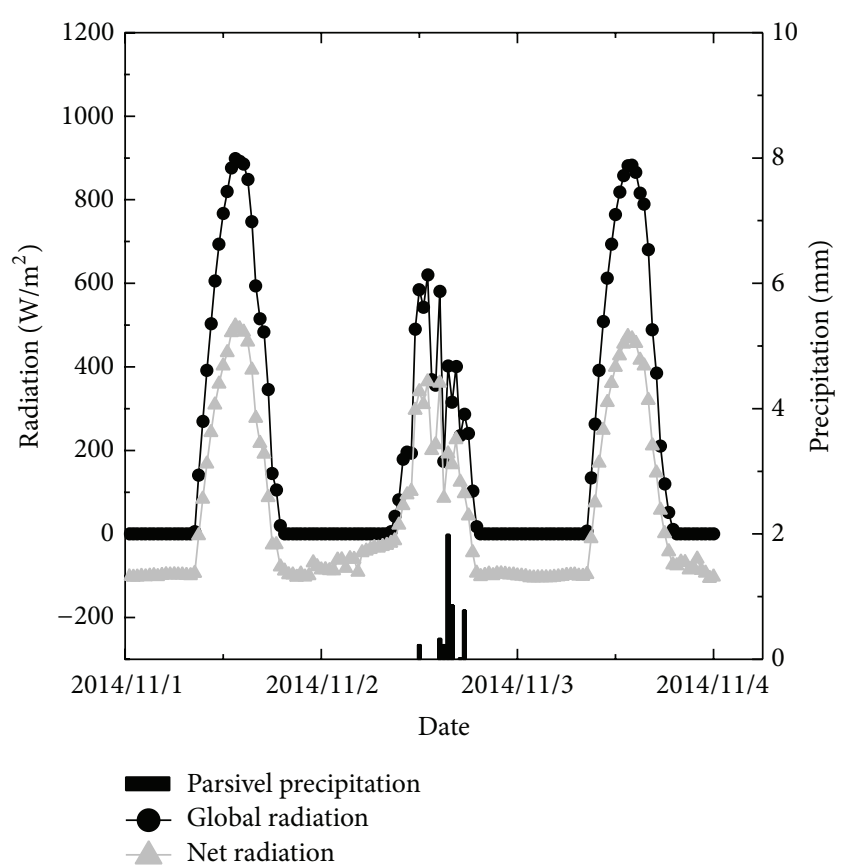

(a)

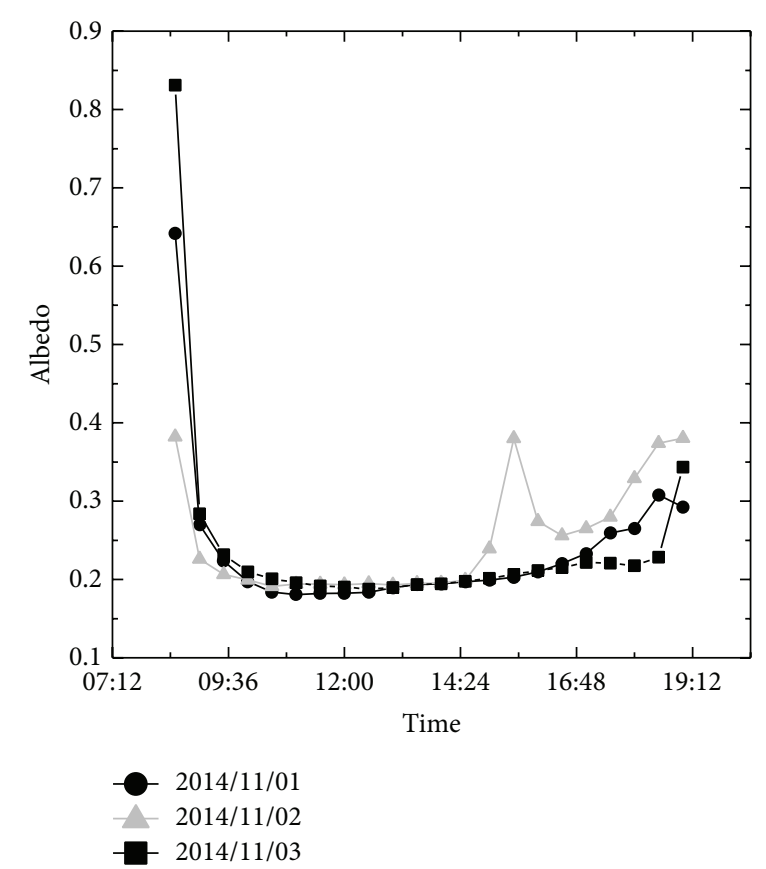

(b)

FIGURE 4: Variation of the (a) global and net radiation and (b) albedo during a single precipitation event.

The results showed that it was a precipitation day on 2014/11/2. This indicates that the optical instruments can record light precipitation that cannot be recorded by the Geonor.

3.2. Comparison of the Daily Solid Precipitation. The precipitation types recorded by LPM and Parsivel in the interior QTP were very complex in May and September, including drizzle, rain, snow, wet snow, sleet, freezing rain, hail, and mixed precipitation. When the precipitation type was wet snow or sleet, the optical instruments recorded abnormal large precipitation amount; this is because the wet snow particles are easier to agglutinate, and both LPM and Parsivel use the equivalent diameter for calculating the precipitation; the agglutinated particles will increase the observation errors. In this study, we removed the wet snow precipitation days when comparing the daily solid precipitation. In BLH station, all of the three methods introduced in Section 2.3 were used to correct the precipitation recorded by Geonor, and the corrected precipitation was compared with the precipitation recorded by LPM (Figure 5). It was shown in Figure 5(a) that the daily precipitation measured by Geonor $\left(P_{\text {Geonor }}\right)$ was smaller than LPM $\left(P_{\mathrm{LPM}}\right)$. After correction by the three methods, the precipitation measured by Geonor was in good agreement with $P_{\text {LPM }}$ (Figures 5(b), 5(c), and 5(d)). The mean absolute error (MAE) was used for assessing the consistency between daily $P_{\mathrm{LPM}}$ and the corrected Geonor based on the three methods:

$$
\mathrm{MAE}=\frac{1}{n} \sum_{i=1}^{n}\left|P_{\mathrm{LPM}}(i)-P_{c-\text { Geonor }}(i)\right|
$$

where $n$ is the sample size, $P_{\mathrm{LPM}}$ is the daily precipitation recorded by LPM (mm), and $P_{c \text {-Geonor }}$ is the corrected Geonor precipitation $(\mathrm{mm})$. The results showed that the daily $P_{\mathrm{LPM}}$ are in best agreement with $P_{\text {Geonor }}$ corrected by Smith's method with the MAE $=0.47 \mathrm{~mm}$.

The scattergram of daily corrected Geonor precipitation $\left(P_{c \text {-Geonor }}\right)$ and precipitation recorded by Parsivel $\left(P_{\text {Parsivel }}\right)$ in TGL station were shown in Figure 6; the daily $P_{c \text {-Geonor }}$ by the three correction methods were still much smaller than $P_{\text {Parsivel }}$. Furthermore, the precipitation amount during 2014/10/1 and 2015/4/30 in TGL station recorded by Parsivel was $305 \mathrm{~mm}$; this disagrees with the reality of the interior QTP. Therefore, we proposed that the Parsivel overestimated the solid precipitation in these regions. Boudala et al. [40] compared the solid precipitation rate and the total precipitation derived from three instruments (Pluvio, Parsivel, and PD12P) on Whistler Mountain in Canada and also proposed that the Parsivel overestimated the solid precipitation, which is consistent with the conclusion in our study.

\subsection{Assessing Geonor's Deficiency in Recording Light Solid} Precipitation. The precipitation gauge includes the DFIR which cannot detect the light solid precipitation under the wind conditions [8]. In this section, Geonor's deficiency in recording light solid precipitation in the interior QTP had also been investigated. 75 precipitation events at different precipitation amount and wind speed recorded by LPM were used for finding the light precipitation threshold that can be detected by the Geonor. It can be seen from Figure 7 that when the wind speeds (WS) were larger than $3.5 \mathrm{~m} / \mathrm{s}$, the Geonor nearly could not record the precipitation events when 


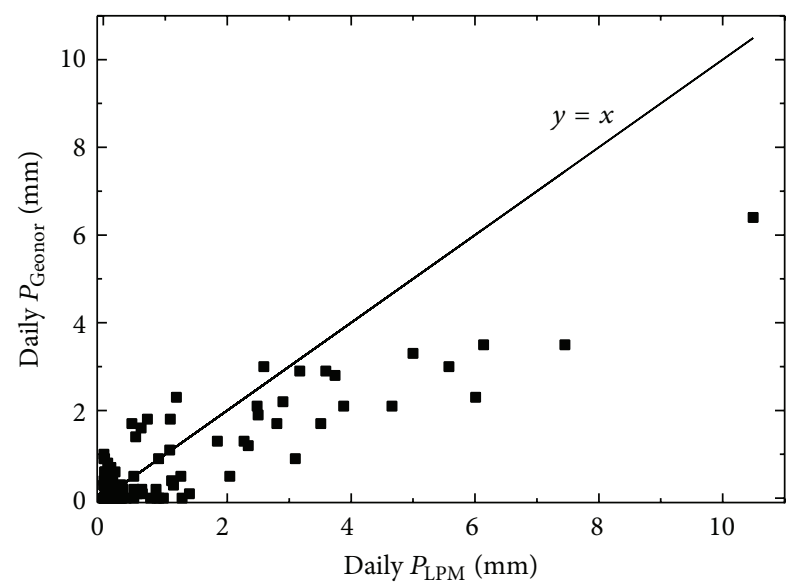

(a)

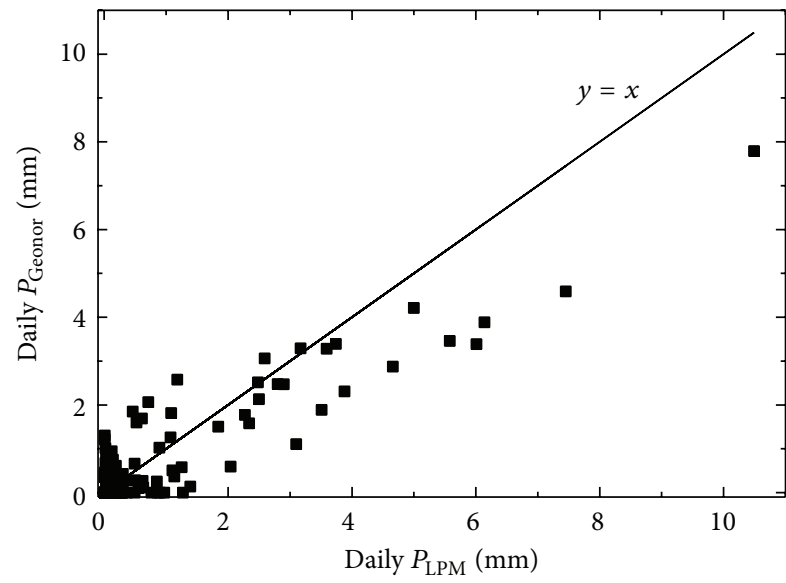

(c)

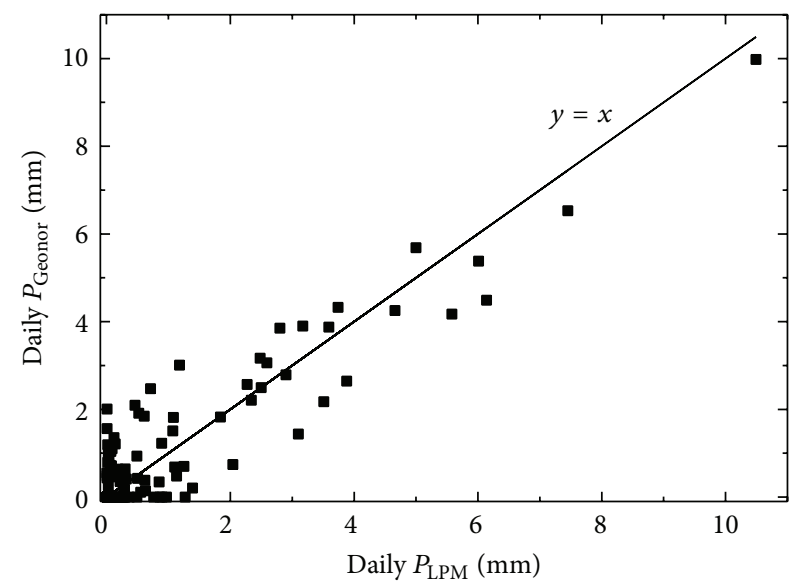

(b)

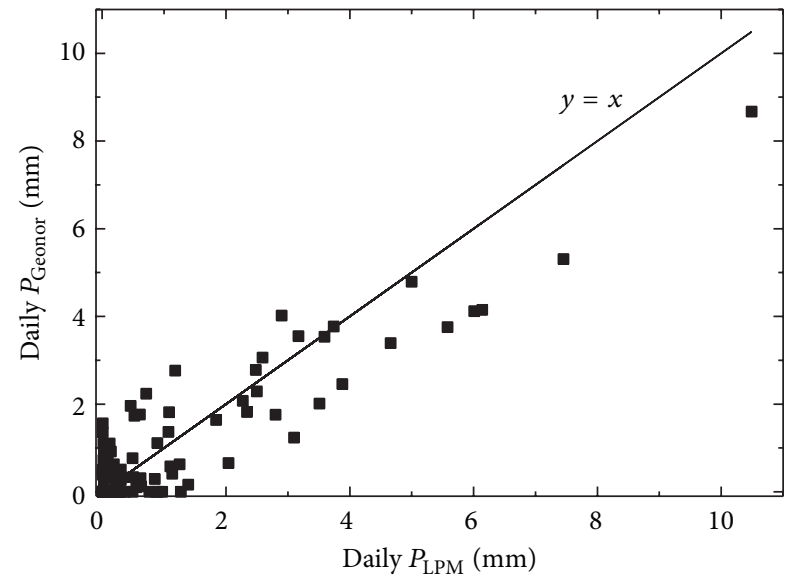

(d)

FIGURE 5: Comparing the daily solid precipitation derived from LPM with (a) Geonor's original precipitation; corrected precipitation by methods proposed by (b) Smith, (c) MacDonald and Pomeroy, and (d) Zhao et al. in the BLH station.

the amount was smaller than $1 \mathrm{~mm}$. Even when $0.5<\mathrm{WS}<$ $3.5 \mathrm{~m} / \mathrm{s}$, about $44 \%$ of these light precipitation still could not be recorded by Geonor.

3.4. Correcting Geonor's Hourly Solid Precipitation. In some of the meteorological and hydrological fields, daily precipitation data are far from perfect for subdaily research. Correcting the hourly solid precipitation is also necessary in the interior QTP. When correcting the gauge measurements of daily solid precipitation, it is generally believed that the catch efficiency (CE) of the precipitation gauge has an exponential relationship with the wind speed. In this study, we took the LPM precipitation as the reference values and calculated the hourly $\mathrm{CE}$ of Geonor $\left(\mathrm{CE}_{\mathrm{Geonor}}\right)$. The exponential function was chosen for fitting the relationship between the wind speed at gauge height (WS) and $\mathrm{CE}_{\mathrm{Geonor}}$ (Figure 8; only both hourly $P_{\text {Geonor }}$ and $P_{\mathrm{LPM}}$ larger than $0.5 \mathrm{~mm}$ are used):

$$
\mathrm{CE}_{\mathrm{Geonor}}=\frac{P_{\mathrm{Geonor}}}{P_{\mathrm{LPM}}}=1.017 \exp (-0.22 \mathrm{WS}) \text {. }
$$

The regression is statistically significance with $F$ value $=$ 96.8 and $\alpha<0.01$ by using the $F$ test. However, it is important to note that the data are scattered. One possible explanation is that the frequency of light precipitation is high in these regions; the Geonor has large system errors when recording the light precipitation.

\section{New Method for Calculating the Parsivel Solid Precipitation Amount}

By comparing the daily solid precipitation recorded by Parsivel with the corrected Geonor, we found that the Parsivel overestimated the solid precipitation amount in the interior QTP. Normally, the Parsivel can directly measure the number and the falling velocity of particles with different sizes. In this study, we recalculated the precipitation amount by using the size and number of snow particle. The computational formula is as follows:

$$
P=\frac{\pi}{6 A} \sum_{j=1}^{t} \sum_{i=1}^{32} N_{i}\left(\alpha D_{i}\right)^{3} \frac{\rho_{\text {snow }}}{\rho_{\text {water }}},
$$




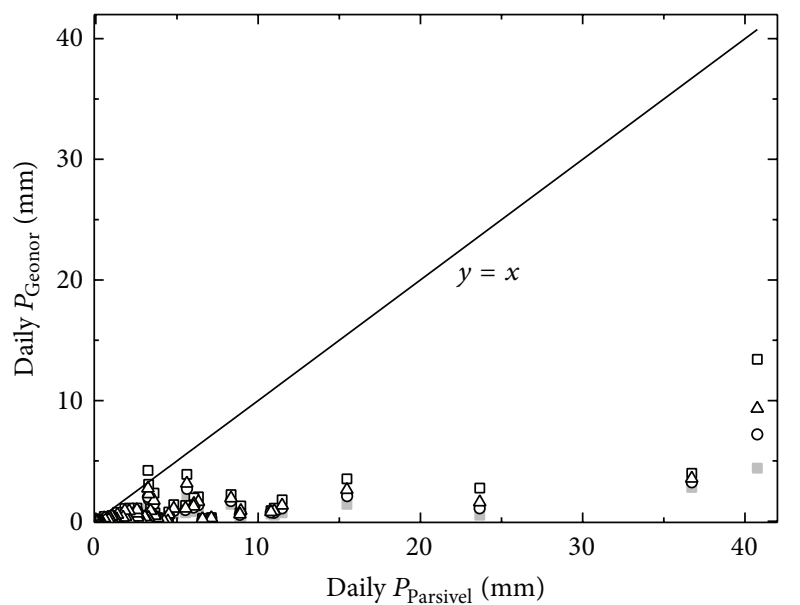

- Geonor's original precipitation data

a Corrected by Smith's method

- Corrected by MacDonald and Pomeroy's method

$\Delta$ Corrected by Zhao et al.s method

FIGURE 6: Comparing the daily solid precipitation derived from Parsivel with Geonor's original and corrected precipitation in TGL station.

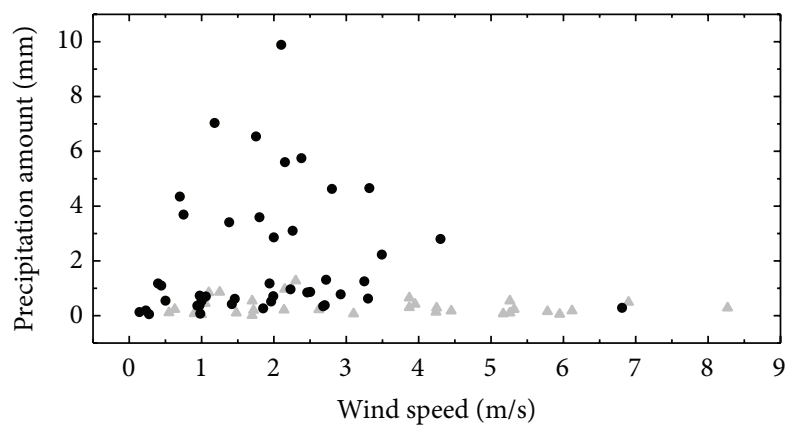

$\Delta$ Precipitation events cannot be recorded by Geonor

- Precipitation events can be recorded by Geonor

FIGURE 7: Precipitation threshold that can be detected by the Geonor under different wind conditions.

where $P$ is the solid precipitation amount $(\mathrm{mm}), t$ is the precipitation duration (minutes), $A$ is the sampling area $\left(\mathrm{mm}^{2}\right), D_{i}(\mathrm{~mm})$ and $N_{i}$ are the diameter of particles class $i$ and corresponding particle numbers, $\alpha$ is the snow particles diameter correction factor, and $\rho_{\text {snow }}\left(\mathrm{kg} / \mathrm{m}^{3}\right)$ and $\rho_{\text {water }}$ $\left(\mathrm{kg} / \mathrm{m}^{3}\right)$ are density of snow and water, respectively. When calculating the SPC solid precipitation, Sugiura et al. [8] set the $\rho_{\text {snow }}$ as $917 \mathrm{~kg} / \mathrm{m}^{3}$; this value was also used in this study.

\subsection{Determination of Snow Particles Diameter Correction} Factor $(\alpha)$. To acquire accurate solid precipitation amount from Parsivel, it is necessary to get the equivalent diameter of each snow particle. Compared with the raindrop, the shape of snow grain is more irregular. It is still a challenge to get the equivalent diameter of snow grains. In this study, the particles diameter correction factor $(\alpha)$ was proposed to get

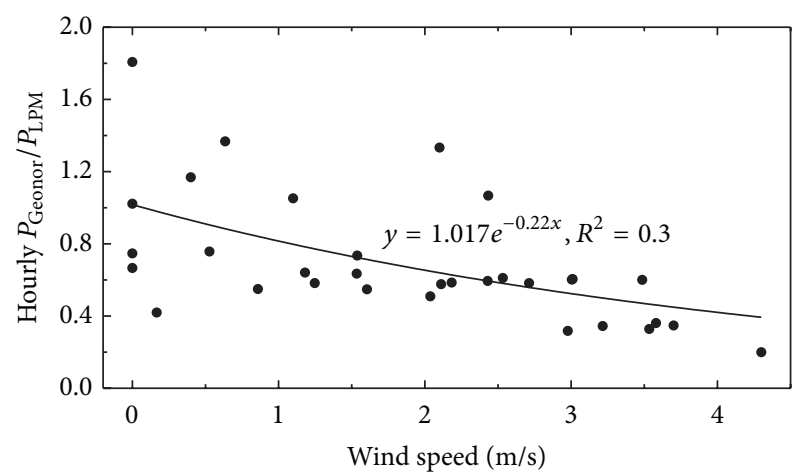

FIGURE 8: Relationship between the hourly $P_{\mathrm{Geonor}} / P_{\mathrm{LPM}}$ and the wind speed (WS).

the equivalent diameter of snow grains; a statistical approach was used for the calculation of $\alpha$; the calculation processes were as follows:

(1) Equation (7) was used for correction of Geonor's halfhour solid precipitation with small wind speed and setting the corrected precipitation amount $\left(P_{c \text {-Geonor }}\right)$ as the "true" value.

(2) Choose the corresponding snow particle information and use (8) for calculation. Considering the small particles $(D<1 \mathrm{~mm})$ are mainly single grain and the larger particles $(D>1 \mathrm{~mm})$ are mainly granular aggregate based on the field observation, the calculation was divided into two parts as follows:

$$
\begin{aligned}
& \frac{\pi}{6 A} \sum_{j=1}^{t} \sum_{i=1}^{8} N_{i}\left(\alpha_{D<1} D_{i}\right)^{3} \frac{\rho_{\text {snow }}}{\rho_{\text {water }}} \\
& +\frac{\pi}{6 A} \sum_{j=1}^{t} \sum_{i=9}^{32} N_{i}\left(\alpha_{D>1} D_{i}\right)^{3} \frac{\rho_{\text {snow }}}{\rho_{\text {water }}}=P_{c \text {-Geonor }},
\end{aligned}
$$

where $\alpha_{D<1}$ is the snow particles diameter correction factor when $D<1 \mathrm{~mm}$ and $\alpha_{D>1}$ is the correction factor when $D>1 \mathrm{~mm}$. The meaning of other parameters was the same with (8).

(3) The least square method was used to calculate $\alpha_{D<1}$ and $\alpha_{D>1}$.

Based on the above method, 81 samples with wind speed smaller than $3 \mathrm{~m} / \mathrm{s}$ in TGL station were chosen to determine $\alpha$ in the interior QTP, and the results were $\alpha_{D<1}=0.72$ and $\alpha_{D>1}=0.3446$.

4.2. Recalculation of Monthly and Daily Solid Precipitation in TGL Station. Based on (8), the monthly solid precipitation derived from Parsivel was recalculated. In the WDL station, the routine meteorological data were missing during the study periods; we only compared recalculated Parsivel's monthly precipitation with Geonor's corrected precipitation in TGL station; the results were shown in Figure 9. During the study periods, the total precipitation amount recorded 


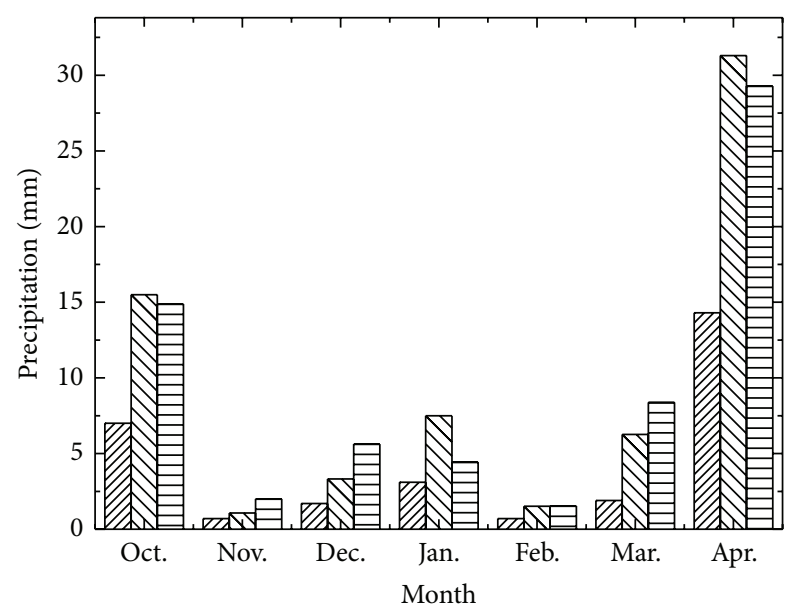

VIIA $P_{\text {Geonor }}$

MIV $P_{c \text {-Geonor }}$

E $P_{r \text {-Parsivel }}$

FIGURE 9: Comparing the monthly recalculated Parsivel solid precipitation with the corrected Geonor precipitation.

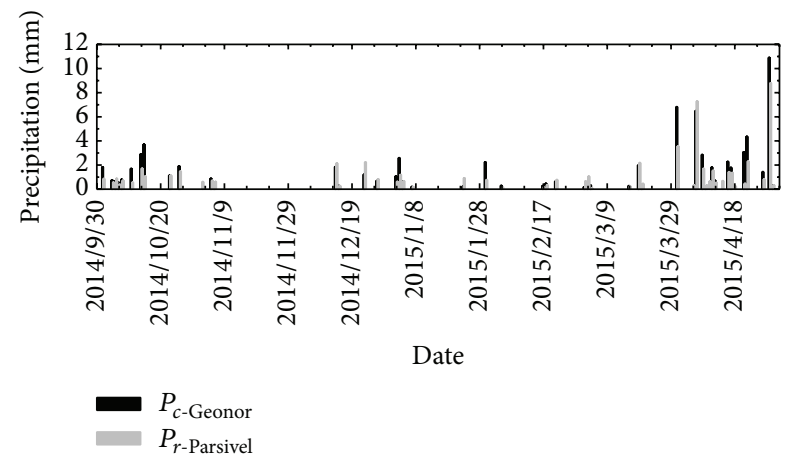

FIGURE 10: Comparing the daily recalculated Parsivel solid precipitation with the corrected Geonor precipitation in TGL station.

by Geonor is $29.4 \mathrm{~mm}$, and Geonor's total precipitation had increased to $66.5 \mathrm{~mm}$ after correction. After recalculation, Parsivel's total precipitation was $66 \mathrm{~mm}$ during this period, which was nearly equal to the corrected Geonor's. It was important to note that there were still differences between the recalculated Parsivel $\left(P_{r \text {-Parsivel }}\right)$ and the corrected Geonor $\left(P_{c \text {-Geonor }}\right)$ at monthly scale, especially when the monthly precipitation was small, and the differences were larger. This was also related with Geonor's bad performance in recording light precipitation.

The recalculated daily solid precipitation of Parsivel $\left(P_{r \text {-Parsivel }}\right)$ was also compared with the corrected Geonor $\left(P_{c \text {-Geonor }}\right)$ by $(7)$; the results were shown in Figure $10 . \mathrm{By}$ using the new calculation method, the $P_{r \text {-Parsivel value was }}$ close to $P_{c \text {-Geonor }}$ based on the method proposed in this study. That means that the new calculation method is suitable for recalculating Parsivel's solid precipitation in the interior QTP.

\section{Discussions and Conclusions}

By comparing the solid precipitation amount derived from the Geonor precipitation gauge with LPM and Parsivel in the three meteorological stations in the interior QTP. We came to the conclusions that the Geonor nearly could not catch the light precipitation (the precipitation amount is less than $1 \mathrm{~mm}$ during a event) when the wind speed was larger than $3.5 \mathrm{~m} / \mathrm{s}$. Even when the wind speed was smaller than $3.5 \mathrm{~m} / \mathrm{s}$, about $44 \%$ of that light precipitation event still could not be recorded by Geonor. However, the light precipitation is dominant and the wind is strong in winter in the interior QTP. According to our statistics, based on the LPM data in the BLH station, the light precipitation events (the precipitation amount is less than $1 \mathrm{~mm}$ during a event) accounted for more than $75 \%$ of the total precipitation events in the cold season. So the challenges for getting accurate solid precipitation in the interior QTP are not only correcting the precipitation gauge's catch efficiency, but also catching the light precipitation in these regions.

LPM and Parsivel could detect light solid precipitation that remains and could not detected by Geonor and some other traditional precipitation gauges. By comparing the daily solid precipitation derived from LPM and Parsivel with the corrected Geonor precipitation, we found that LPM can record credible solid precipitation in the interior QTP. However, Parsivel overestimated the precipitation amount. Finally, we concluded that LPM can be effectively conducted in the interior QTP. Taking the LPM's solid precipitation as the reference value, we also proposed a method for correcting Geonor's solid precipitation at the hourly scale.

In order to get the credible solid precipitation from Parsivel, a new precipitation calculation formula by just using the size and number of snow particles had been proposed in this study, and the diameter correction factor of snow particles was determined by the statistical method. By using the new calculation formula, the accuracy of solid precipitation amount derived form Parsivel had been improved.

In summary, the optical instruments have large potential in recording more accurate solid precipitation and they are also powerful tools for recording the high frequency light precipitation in the interior QTP. However, it should be mentioned that both LPM and Parsivel have large errors when used for measuring mixed precipitation. Further efforts need to be made next.

\section{Conflict of Interests}

The authors declare that there is no conflict of interests regarding the publication of this paper.

\section{Acknowledgments}

This research was supported by Key Project of Nation Natural Science Foundation of China (2013CBA01803), the National Natural Science Foundation of China (41271081 and 41271086), the Youth Science Fund of China (41401085), the Hundred Talents Program of Chinese Academy of Sciences 
(51Y551831), and the Key Deployment Project of Chinese Academy of Sciences (KJZD-EW-G03-02).

\section{References}

[1] Y. Zhang, T. Ohata, D. Yang, and G. Davaa, "Bias correction of daily precipitation measurements for Mongolia," Hydrological Processes, vol. 18, no. 16, pp. 2991-3005, 2004.

[2] D. Yang and T. Ohata, "A bias-corrected Siberian regional precipitation climatology," Journal of Hydrometeorology, vol. 2, no. 2, pp. 122-139, 2001.

[3] J. M. Thériault, R. Rasmussen, K. Ikeda, and S. Landolt, "Dependence of snow gauge collection efficiency on snowflake characteristics," Journal of Applied Meteorology and Climatology, vol. 51, no. 4, pp. 745-762, 2012.

[4] V. Nešpor and B. Sevruk, "Estimation of wind-induced error of rainfall gauge measurements using a numerical simulation," Journal of Atmospheric and Oceanic Technology, vol. 16, no. 4, pp. 450-464, 1999.

[5] T. J. Garrett and S. E. Yuter, "Observed influence of riming, temperature, and turbulence on the fallspeed of solid precipitation," Geophysical Research Letters, vol. 41, no. 18, pp. 6515-6522, 2014.

[6] J. C. Adam and D. P. Lettenmaier, "Adjustment of global gridded precipitation for systematic bias," Journal of Geophysical Research D: Atmospheres, vol. 108, no. 9, 2003.

[7] D. Yang, D. Kane, Z. Zhang, D. Legates, and B. Goodison, "Bias corrections of long-term (1973-2004) daily precipitation data over the northern regions," Geophysical Research Letters, vol. 32, no. 19, Article ID L19501, 2005.

[8] K. Sugiura, T. Ohata, D. Yang, T. Sato, and A. Sato, "Application of a snow particle counter to solid precipitation measurements under Arctic conditions," Cold Regions Science and Technology, vol. 58, no. 1-2, pp. 77-83, 2009.

[9] D. Yang and A. Simonenko, "Comparison of winter precipitation measurements by six tretyakov gauges at the valdai experimental site," Atmosphere-Ocean, vol. 52, no. 1, pp. 39-53, 2014.

[10] R. Rasmussen, B. Baker, J. Kochendorfer et al., "How well are we measuring snow: the NOAA/FAA/NCAR winter precipitation test bed," Bulletin of the American Meteorological Society, vol. 93, no. 6, pp. 811-829, 2012.

[11] K. Sugiura, D. Yang, and T. Ohata, "Systematic error aspects of gauge-measured solid precipitation in the Arctic, Barrow, Alaska," Geophysical Research Letters, vol. 30, no. 4, pp. 41-1, 2003.

[12] D. Yang, "Double Fence Intercomparison Reference (DFIR) vs. Bush Gauge for 'true' snowfall measurement," Journal of Hydrology, vol. 509, pp. 94-100, 2014.

[13] B. Ye, D. Yang, Y. Ding, T. Han, and T. Koike, "A bias-corrected precipitation climatology for China," Journal of Hydrometeorology, vol. 5, no. 6, pp. 1147-1160, 2004.

[14] Y. Ding, D. Yang, B. Ye, and N. Wang, "Effects of bias correction on precipitation trend over China," Journal of Geophysical Research: Atmospheres, vol. 112, no. 13, Article ID D13116, 2007.

[15] Y. Ma, Y. Zhang, D. Yang, and S. B. Farhan, "Precipitation bias variability versus various gauges under different climatic conditions over the Third Pole Environment (TPE) region," International Journal of Climatology, vol. 35, no. 7, pp. 1201-1211, 2015.

[16] R. Chen, J. Liu, E. Kang et al., "Precipitation measurement intercomparison in the Qilian Mountains, Northeastern Tibetan
Plateau," The Cryosphere Discussions, vol. 9, no. 2, pp. 2201-2230, 2015.

[17] K. Ueno, H. Fujii, H. Yamada, and L. Liu, "Weak and frequent monsoon precipitation over the Tibetan plateau," Journal of the Meteorological Society of Japan, vol. 79, no. 1, pp. 419-434, 2001.

[18] H. I. Bloemink and E. Lanzinger, "Precipitation type from the Thies disdrometer," in Proceedings of the WMO Technical Conference on Instruments and Methods of Observation, pp. 4-7, Bucharest, Romania, 2005.

[19] E. Lanzinger, M. Theel, and H. Windolph, "Rainfall amount and intensity measured by the Thies laser precipitation monitor," in Proceedings of the WMO Technical Conference on Meteorological and Environmental Instruments and Methods of Observation (TECO '06), pp. 2-6, Geneva, Switzerland, December 2006.

[20] R. P. de Moraes Frasson, L. K. da Cunha, and W. F. Krajewski, "Assessment of the Thies optical disdrometer performance," Atmospheric Research, vol. 101, no. 1-2, pp. 237-255, 2011.

[21] A. Tokay, D. B. Wolff, and W. A. Petersen, "Evaluation of the new version of the laser-optical disdrometer, OTT parsivel," Journal of Atmospheric and Oceanic Technology, vol. 31, no. 6, pp. 12761288, 2014.

[22] A. Battaglia, E. Rustemeier, A. Tokay, U. Blahak, and C. Simmer, "PARSIVEL snow observations: a critical assessment," Journal of Atmospheric and Oceanic Technology, vol. 27, no. 2, pp. 333-344, 2010.

[23] Z. Lin, F. Niu, H. Liu, and J. Lu, "Hydrothermal processes of Alpine Tundra Lakes, Beiluhe Basin, Qinghai-Tibet Plateau," Cold Regions Science and Technology, vol. 65, no. 3, pp. 446-455, 2011.

[24] Z. Lin, F. Niu, Z. Xu, J. Xu, and P. Wang, "Thermal regime of a thermokarst lake and its influence on permafrost, Beiluhe Basin, Qinghai-Tibet Plateau," Permafrost and Periglacial Processes, vol. 21, no. 4, pp. 315-324, 2010.

[25] J. Yao, L. Zhao, Y. Ding et al., “The surface energy budget and evapotranspiration in the Tanggula region on the Tibetan Plateau," Cold Regions Science and Technology, vol. 52, no. 3, pp. 326-340, 2008.

[26] Y. Xiao, L. Zhao, R. Li et al., "The characteristics of surface albedo in permafrost regions of northern Tibetan plateau," Journal of Glaciology and Geocryology, vol. 32, no. 6, pp. 480488, 2010 (Chinese).

[27] L. Zhao, R. Li, and Y. Ding, "Simulation on the soil waterthermal characteristics of the active layer in Tanggula Range," Journal of Glaciology and Geocryology, vol. 30, no. 6, pp. 930937, 2008.

[28] X.-B. He, B.-S. Ye, and Y.-J. Ding, "Bias correction for precipitation mesuament in Tanggula Mountain Tibetan Plateau," Advances in Water Science, vol. 20, no. 3, pp. 403-408, 2009 (Chinese).

[29] C. D. Smith, "Correcting the wind bias in snowfall measurements made with a Geonor T-200B precipitation gauge and alter wind shield," in Proceedings of the 87th American Meteorological Society Annual Meeting, San Antonio, Tex, USA, 2007.

[30] J. MacDonald and J. W. Pomeroy, "Gauge undercatch of two common snowfall gauges in a prairie environment," in Proceedings of the 64th Eastern Snow Conference, pp. 119-124, St. John's, Canada, June 2007.

[31] M. Hayashi and C. R. Farrow, "Watershed-scale response of groundwater recharge to inter-annual and inter-decadal variability in precipitation (Alberta, Canada)," Hydrogeology Journal, vol. 22, no. 8, pp. 1825-1839, 2014. 
[32] J. Zhou, J. W. Pomeroy, W. Zhang, G. Cheng, G. Wang, and C. Chen, "Simulating cold regions hydrological processes using a modular model in the west of China," Journal of Hydrology, vol. 509, pp. 13-24, 2014.

[33] J. L. Hood and M. Hayashi, "Characterization of snowmelt flux and groundwater storage in an alpine headwater basin," Journal of Hydrology, vol. 521, pp. 482-497, 2015.

[34] M. K. MacDonald, J. W. Pomeroy, and A. Pietroniro, "On the importance of sublimation to an alpine snow mass balance in the Canadian Rocky Mountains," Hydrology and Earth System Sciences, vol. 14, no. 7, pp. 1401-1415, 2010.

[35] X. Fang, J. W. Pomeroy, C. R. Ellis, M. K. MacDonald, C. M. Debeer, and T. Brown, "Multi-variable evaluation of hydrological model predictions for a headwater basin in the Canadian Rocky Mountains," Hydrology and Earth System Sciences, vol. 17, no. 4, pp. 1635-1659, 2013.

[36] P. Harder and J. W. Pomeroy, "Hydrological model uncertainty due to precipitation-phase partitioning methods," Hydrological Processes, vol. 28, no. 14, pp. 4311-4327, 2014.

[37] Q. Zhao, B. Ye, X. He, J. Zhang, and C. Zhao, "Bias correction of daily precipitation measured by Geonor T-200B precipitation gauge in Tanggula mountain," Plateau Meteorology, vol. 33, no. 2, pp. 452-459, 2014 (Chinese).

[38] D. Yang, Y. Shi, E. Kang, Y. Zhang, and X. Yang, "Results of solid precipitation measurement intercomparison in the alpine area of Urumqi River Basin," Chinese Science Bulletin, vol. 36, no. 13, pp. 1105-1109, 1991.

[39] B. E. Goodison, P. Y. T. Louie, and D. Yang, "The WMO solid precipitation measurement intercomparison," World Meteorological Organization-Publications-WMO TD, pp. 65-70, 1997.

[40] F. S. Boudala, G. A. Isaac, R. Rasmussen, S. G. Cober, and B. Scott, "Comparisons of snowfall measurements in complex terrain made during the 2010 winter Olympics in Vancouver," Pure and Applied Geophysics, vol. 171, no. 1-2, pp. 113-127, 2014. 

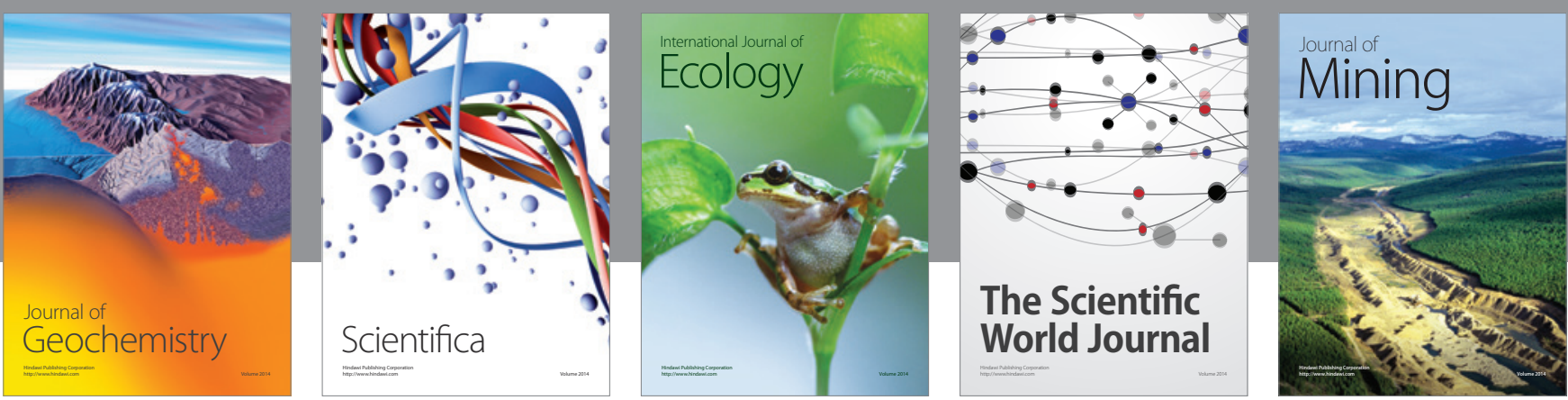

The Scientific World Journal
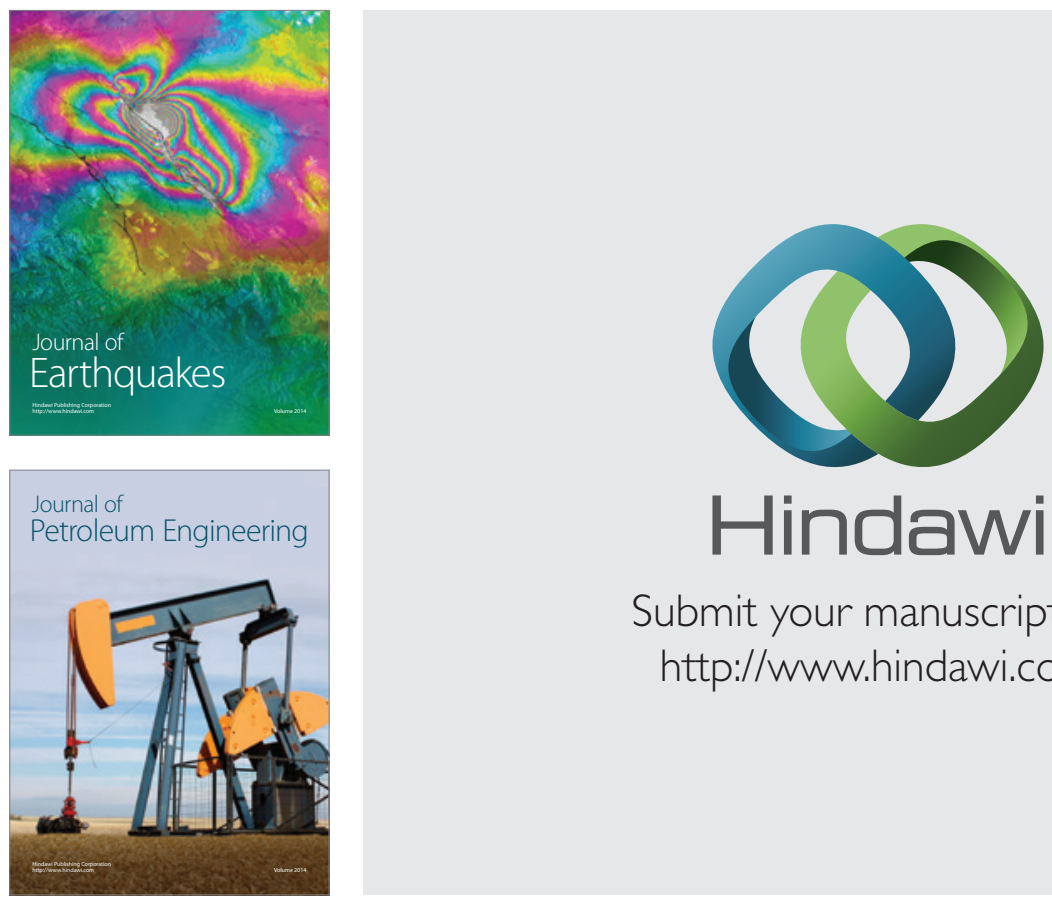

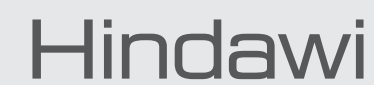

Submit your manuscripts at

http://www.hindawi.com
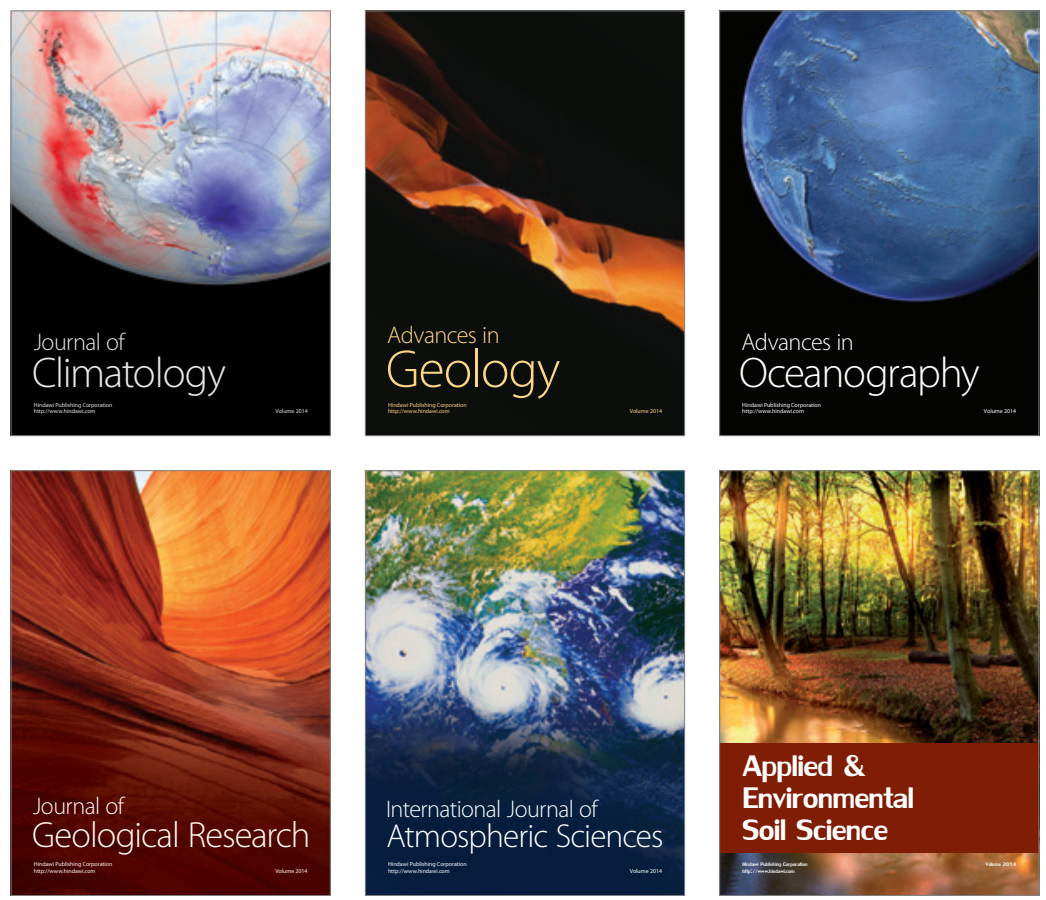
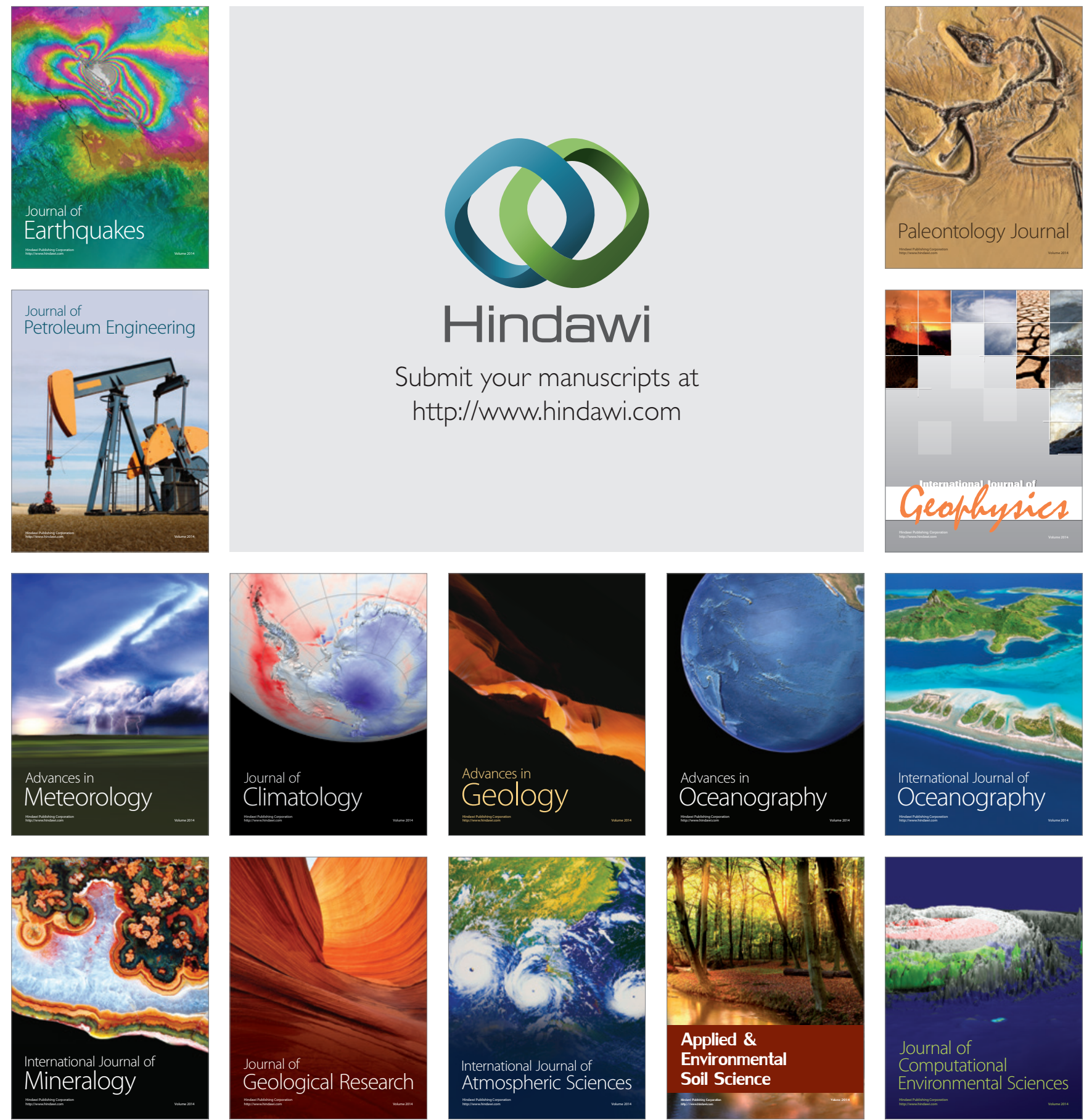